III). Of the diuretics used in Sherlock's series frusemide most closely resembles metolazone in the pattern of electrolyte disturbance which is produced. Metolazone produces more electrolyte disturbance than the thiazides, and this suggests that it is a more powerful diuretic.

Encephalopathy occurred in $35 \%$ of patients compared with $22-28 \%$ in the series of Sherlock et al. (1966) in which thiazides (with or without spironolactone) and frusemide were used. In our study five of the seven patients with encephalonathy had hypokalaemia though this was associated with a diuresis in only three of them. Read et al. (1959) found a high incidence of hypokalaemia in relation to encephalopathy, but Sherlock et al. (1966) found that encephalopathy was related to electrolyte disturbance as a whole rather than to hypokalaemia per se. In the present series four out of seven patients with encephalopathy had a profound electrolyte disturbance, reflecting poor hepatocellular function as well as potent diuretic therapy (Hecker and Sherlock, 1956; Sherlock et al., 1966).

Miscellaneous complaints associated with diuretic therapy were common, especially muscle weakness, which was probably due to hypokalaemia. Nausea and abdominal discomfort could have been due to diuretic therapy or potassium supplements. Cramps and hypotension were associated with hyponatraemia after diuresis. One patient had a rash and eosinophilia; the relationship to diuretic therapy was uncertain as he had had several previous similar episodes. Similarly, the cause of leucopenia in one patient (Case 6) was uncertain; it may have been due to hypersplenism as the patient had pronounced splenomegaly and previous thrombocytopenia, or it could have been due to metolazone, amiloride, or nitrazepam.

Metolazone, therefore, has several major disadvantages: a $\stackrel{\varnothing}{\stackrel{2}{2}}$ high incidence of hypokalaemia $(80 \%)$, hypochloraemia $(35 \%)$,.. and encephalopathy $(35 \%)$. However, the low incidence of $\overrightarrow{\vec{F}}$ azotaemia $(5 \%)$ compared with previous series (Sherlock $\stackrel{5}{\circ}$ et al., 1966) suggests that it may be useful if renal function is greatly impaired.

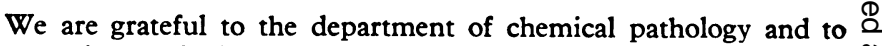
the nursing staff of the Royal Free Hospital for their help. One of us (P.H.) was in receipt of a Stanley Thomas Johnson Fellowship. This work was supported by the Pennwalt Corporation, Rochester, N.Y., U.S.A

\section{References}

Hecker, R., and Sherlock, S. (1956). Lancet, 2, 1121

Read, A. E., Haslam, R. M., Laidlaw, J., and Sherlock, S. (1959). N Clinical Science, 18, 409.

Senewiratne, B., and Sherlock, S. (1968). Lancet, 1, 120.

Shear, L., Ching, S., and Gabuzda, G. J. (1970). New England fournal 음 of Medicine, 282, 1391.

Sherlock, S., Senewiratne, B., Scott, A., and Walker, J. G. (1966). W Lancet, 1, 1049.

\title{
Some Operative and Postoperative Hazards of Legal Termination of Pregnancy
}

\author{
SATYA V. SOOD
}

British Medical fournal, 1971, 4, 270-273

\section{Summary}

Analysis of 1,317 patients admitted for N.H.S. abortion showed an overall morbidity of $16.8 \%$ excluding urinary tract infection. Genital infection, chest infection, reevacuation or perforation of the uterus, and haemorrhage were the more common complications. There was one maternal death.

\section{Introduction}

As a result of the Abortion Act of 1967 therapeutic abortion has become not only an accepted medical procedure, and the only medical procedure controlled by law, but also one of the commonest gynaecological operations. The demand for abortion is still rising. The annual numbers in our unit have shown a remarkable increase from 1960 to 1969 (Table I). The fall in 1970 was due to restriction on abortions owing to the long waiting lists for other gynaecological operations. The number of deliveries has not varied appreciably since 1963. Mortality reports vary enormously from one country to another (Table II).

The Annual Reports of the Chief Medical Officer (1970) indicates that mortality rates showing the highest risk of

\section{West Middlesex Hospital, Isleworth, Middlesex}

SATYA V. SOOD, F.R.C.S.ED., M.R.C.O.G., Senior Registrar in Obstetrics and Gynaecology death are among women aged 35 to 44 years, and also among women whose pregnancies were terminated by hysterotomy $(8 \cdot 4 / 10,000)$ or by hysterectomy $(12 \cdot 6 / 10,000)$. The fatality rate for evacuation of the uterus by aspiration is $2 \cdot 2 / 10,000$ and for all other methods, including dilatation and curettage, it is $0 \cdot 9 / 10,000$. Morbidity is inevitable even with a simple operation, and most methods used in termination of pregnancy are far from simple.

Published estimates of complications after therapeutic TABLE I-Number of Therapeutic Abortions and Deliveries in the West Middlesex Hospital

\begin{tabular}{|c|c|c|c|}
\hline \multicolumn{2}{|c|}{ Year } & No. of Abortions & No. of Deliveries \\
\hline $\begin{array}{l}1960 \\
1961 \\
1962 \\
1963 \\
1964 \\
1965 \\
1966 \\
1967 \\
1968 \\
1969 \\
1970\end{array}$ & $\begin{array}{l}. . \\
\cdots \\
\cdots \\
\cdots \\
\cdots \\
\cdots \\
\cdots \\
\cdots \\
\cdots \\
.\end{array}$ & $\begin{array}{r}1 \\
7 \\
32 \\
32 \\
42 \\
88 \\
192 \\
286 \\
382 \\
468 \\
407\end{array}$ & $\begin{array}{l}1,899 \\
1,086 \\
2,126 \\
2,343 \\
2,549 \\
2,480 \\
2,600 \\
2,493 \\
2,346 \\
2,361 \\
2,468\end{array}$ \\
\hline
\end{tabular}

TABLE II-Mortality Due to Legal Abortion

\begin{tabular}{|c|c|c|c|c|}
\hline Country & Date & $\begin{array}{l}\text { No. of } \\
\text { Abortions }\end{array}$ & $\begin{array}{l}\text { No. of } \\
\text { Deaths }\end{array}$ & $\begin{array}{l}\text { Deaths } / 100,000 \\
\text { Abortions Performed }\end{array}$ \\
\hline $\begin{array}{ll}\text { Denmark } & . \\
\text { Sweden } & . \\
\text { Yugoslavia } & . \\
\text { Japan } & \text { Czechoslovakia } \\
\text { Czungary } & \text {.. }\end{array}$ & $\begin{array}{l}1961-5 \\
1960-6 \\
1960-1 \\
1959-65 \\
1958-64 \\
1963-4\end{array}$ & $\begin{array}{r}21,700 \\
30,600 \\
177,499 \\
6,860,000 \\
561,000 \\
328,200\end{array}$ & $\begin{array}{r}9 \\
12 \\
8 \\
278 \\
12 \\
2\end{array}$ & $\begin{array}{r}41.4 \\
39.2 \\
4.5 \\
4.1 \\
2.1 \\
0.6\end{array}$ \\
\hline
\end{tabular}


abortion vary from 0.9 to $55.6 \%$ (Potts, 1970). The possible reasons for this discrepancy are: (1) the experience of the surgeon and his team, (2) different criteria used in assessment of morbidity, (3) lack of detailed note-keeping, and (4) the patient may not return to the same hospital if a complication develops or she may be treated at home.

The patients discharged after overnight stay may develop a complication which is rarely recorded in hospital notes unless she returns to the same hospital. However, when the operation is performed in healthy women early in pregnancy discharge from hospital on the day of operation is compatible with low morbidity (Potts, 1970).

The figures of the Registrar General probably understate the situation, as not all cases are always notified and of ten the form is filled at or soon after the operation when only the most immediate complications are recorded.

\section{Present Series}

This retrospective series covers the period of four years from January 1967 to December 1970. The number of operations was 1,543 , including $159(10 \cdot 2 \%)$ private patients and 67 $(4.3 \%)$ one-day cases. These private patients and one-day cases have been excluded, as there was lack of adequate information, leaving 1,317 National Health Service patients whose records were analysed- 630 were in the first trimester, 683 in the second, and four in the third. Five patients decided to continue with the pregnancy; at operation five patients were found not to be pregnant. This series includes one patient aged 13 years and 10 aged 14 years. The oldest patient was a woman of 47 separated from her husband. The operations were carried out by doctors of all grades and of varying experience. Consultants carried out $10 \%$ of the operations. Analysis by age and marital status is given in Table III.

TABLE III-Analysis by Age and Marital Status

\begin{tabular}{l|c|c|c|c|c|c|c|c|c}
\hline & -15 & $16-$ & $21-$ & $26-$ & $31-$ & $36-$ & $41-$ & $46+$ & Total (\%) \\
\hline Single & 38 & 255 & 166 & 53 & 18 & 9 & 4 & 2 & $545(41 \cdot 4)$ \\
Married & 0 & 17 & 140 & 181 & 160 & 111 & 35 & 3 & $647(49 \cdot 1)$ \\
Divorced & 0 & 0 & 5 & 13 & 9 & 9 & 1 & 1 & $38(2 \cdot 9)$ \\
Separated & 0 & 8 & 24 & 20 & 13 & 9 & 4 & 1 & $79(6 \cdot 0)$ \\
Widow & 0 & 1 & 0 & 2 & 3 & 2 & 0 & 0 & $8(0 \cdot 6)$ \\
\hline $\begin{array}{l}\text { Total } \\
\%\end{array}$ & 38 & 281 & 335 & 269 & 203 & 140 & 44 & 7 & 1,317 \\
& $2 \cdot 9$ & $21 \cdot 3$ & $25 \cdot 4$ & $20 \cdot 4$ & $14 \cdot 6$ & $10 \cdot 6$ & $3 \cdot 3$ & 0.5 & \\
& & & & & & & &
\end{tabular}

\section{Choice of Technique}

Choice of technique was decided by the consultant in charge of the case. Vaginal termination by dilatation and curettage was the method of choice up to 14 weeks' gestation, except where sterilization was indicated. Since 1969 we have increasingly used the vacuum aspiration technique, using Bierer's apparatus.

During hysterotomy the low vertical incision was used in most cases because of less danger of extension towards the uterine vessels. In 15 cases hysterectomy was preferred be-

TABLE IV-Method Used and Duration of Gestation

\begin{tabular}{|c|c|c|c|c|c|c|c|}
\hline $\begin{array}{c}\text { Duration } \\
\text { in } \\
\text { Weeks }\end{array}$ & $\begin{array}{l}\text { Dilatation } \\
\text { and } \\
\text { Curettage }\end{array}$ & $\begin{array}{c}\text { Suction } \\
\text { Evacua- } \\
\text { tion }\end{array}$ & $\begin{array}{l}\text { Utus } \\
\text { Paste }\end{array}$ & $\begin{array}{c}\text { Hyster- } \\
\text { otomy }\end{array}$ & $\begin{array}{c}\text { Hyster- } \\
\text { otomy and } \\
\begin{array}{c}\text { Steriliza- } \\
\text { tion }\end{array}\end{array}$ & $\begin{array}{l}\text { Hyster- } \\
\text { ectomy }\end{array}$ & Total $(\%)$ \\
\hline $\begin{array}{l}\text { Up to } 8 \\
9-12 \\
13-16 \\
17-20 \\
20-24 \\
25-28\end{array}$ & $\begin{array}{r}49 \\
352 \\
152 \\
3 \\
0 \\
0\end{array}$ & $\begin{array}{r}25 \\
130 \\
43 \\
0 \\
0 \\
0\end{array}$ & $\begin{array}{r}0 \\
10 \\
60 \\
13 \\
0 \\
0\end{array}$ & $\begin{array}{r}1 \\
4 \\
108 \\
67 \\
31 \\
3\end{array}$ & $\begin{array}{r}6 \\
50 \\
128 \\
52 \\
16 \\
1\end{array}$ & $\begin{array}{l}1 \\
2 \\
8 \\
2 \\
0 \\
0\end{array}$ & $\begin{array}{c}82(6 \cdot 2) \\
548(41 \cdot 6) \\
499(37 \cdot 8) \\
137(10 \cdot 4) \\
47(3 \cdot 6) \\
4(0 \cdot 3)\end{array}$ \\
\hline $\begin{array}{l}\text { Total } \\
\%\end{array}$ & $\begin{array}{l}556 \\
42 \cdot 2\end{array}$ & $\begin{array}{l}198 \\
15.0\end{array}$ & $\begin{array}{r}83 \\
6.3\end{array}$ & $\begin{array}{l}214 \\
17 \cdot 0\end{array}$ & $\begin{array}{l}253 \\
19 \cdot 2\end{array}$ & $\begin{array}{c}13 \\
0.9\end{array}$ & 1,317 \\
\hline
\end{tabular}

cause of associated uterine morbidity. Routine catheterization was done to empty the bladder preoperatively in all abdominal operations but not in the case of vaginal termination where this was left to the discretion of the surgeon. The method used and the duration of gestation is shown in Table IV.

\section{Complications}

Many major and minor complications occurred in this series. There was one death. Most patients were seen six weeks after the operation; longer follow-up was not attempted. Complications occurring after vaginal and abdominal termination are compared.

\section{PYREXIA}

Pyrexia of $100^{\circ} \mathrm{F}\left(37.8^{\circ} \mathrm{C}\right)$ for three days or more requiring antibiotic therapy occurred in $27 \%$ of the patients- $3.5 \%$ were cases of pyrexia of unknown origin.

\section{INFECTION}

Urinary Tract Infection.-This was diagnosed if the midstream specimen showed more than 100,000 organisms per $\mathrm{ml}$ and more than 5 pus cells per high-power field. These occurred in $215(44.8 \%)$ out of 480 abdominal operations. Routine preoperative catheterization was undertaken after routine swabbing with Cetrimide without previously sterilizing the urethra or instilling chlorhexidine or Noxyflex at the end of catheterization. Urinary infection followed $70(8.4 \%)$ vaginal operations. However, catheterization was not done in these as a routine. The exact number of cases catheterized is unknown. The organisms responsible for infection were: Escherichia coli $48.5 \%$, Proteus spp. 16.0\%, Streptococcus faecalis $13.5 \%$, Paracolon bacilli $4.5 \%$, Staphylococcus pvogenes $3.0 \%$, Str. pyogenes $1.0 \%$, Achromobacter spp. 0.7\%, Pseudomonas pyocyanea $0.7 \%$, Trichomonas vaginalis $0.7 \%$, Klebsiella spp. $0.3 \%$, Monilia spp. $0.3 \%$, Staph. saprophyticus $0.3 \%$, Mixed organisms $10.5 \%$.

Genital Infection.-This occurred in $37(2.8 \%)$ cases, including two which followed hysterotomy. Endometritis was diagnosed in 15 and was associated with parametritis in 13. There were two cases of salpingo-oophoritis. Pelvic abscess developed in two cases, both after perforation at the time of insertion of Utus paste or subsequent dilatation and curettage, but was not diagnosed at the time-in one the pelvic mass responded to antibiotic therapy but the other patient developed a pelvic abscess after discharge from hospital and eventually died at home (Sood, 1971). One case of uterine infection and one case of pyometra followed abdominal hysterotomy.

Septicaemia.-This occurred in three cases, and pregnancy was terminated by intrauterine insertion of Utus paste in all of them. These cases have been reported elsewhere (Sood, 1971).

Chest Infection.-Pulmonary infection occurred postoperatively in $18(3.8 \%)$ cases after abdominal operations. In seven the infection was of "severe" degree. In most patients the response to antibiotic therapy was satisfactory. One case had partial atelectasis of one lung and another had total collapse of one lung. In contrast there was only one case $(0.1 \%)$ of chest infection after vaginal termination.

\section{WOUND COMPLICATIONS}

Infection of varying degrees occurred in $26(2.0 \%)$ patients. Wound dehiscence followed in three cases and the skin edges had to be resutured. Two patients had a burst abdomen, 
and one of these developed paralytic ileus which responded satisfactorily to gastric aspiration, "drip therapy," and sedation. A wound haematoma occurred in three cases-in one it involved half the anterior abdominal wall. At the six-week follow-up examination one patient was also found to have an incisional hernia and this was subsequently repaired.

\section{RE-EVACUATION OF THE UTERUS}

The main reasons for this were irregular vaginal bleeding, excessive vaginal discharge, signs of low-grade uterine infection, or a combination of these. Re-evacuation was needed in $80(9.5 \%)$ of cases terminated vaginally. On 41 occasions re-evacuation was necessary after the patient had been discharged from the hospital. In $32(3.8 \%)$ cases irregular vaginal bleeding due to retained products of conception was the main indication; this is a much higher figure than those reported previously (Lakomy, 1968; Sternadel et al., 1968; Diggory, 1969).

Re-evacuation was needed after abdominal hysterectomy in $11(2.3 \%)$ cases. In all these the indication were irregular bleeding due to retained products of conception.

\section{ANAEMIA}

Anaemia was diagnosed if the haemoglobin was below $70 \%$ $(10.0 \mathrm{~g})$ and there was a fall of at least $15 \%$ from the preoperative reading. This occurred in 24 cases $(3.0 \%)$ after vaginal termination and $16(2.8 \%)$ cases after abdominal operation.

\section{SEVERE HAEMORRHAGE}

All abortions are associated with bleeding from the endometrium and the placental site, the estimates of haemorrhage varying in different series (Vladov et al., 1965; Kerslake and Casey, 1967). Lindahl (1959) reported on a series of 1,000 abortions from Sweden and though over half the pregnancies were terminated after 17 weeks there were 32 cases of severe haemorrhage. In the present series there were $17(2.5 \%)$ cases of severe haemorrhage of more than 1 litre. Seven (1.5\%) occurred after abdominal termination.

Hysterectomy was needed in two cases after abdominal hysterotomy. In one case a 17-year-old para $0+0$ had a hysterotomy at 20 weeks' gestation. After repair of the uterine longitudinal incision the uterus remained flaccid and she continued to bleed. Ergometrine, bimanual compression, hot packs, and ligation of the uterine vessels failed to control haemorrhage. The blood coagulation was normal. In the second case the patient, a married woman of para $4+10$ whose pregnancy was terminated at 17 weeks by hysterotomy, continued to bleed after suture of the uterine incision. All measures to achieve haemostasis failed and a hysterectomy was eventually performed. Her coagulation mechanism was also normal. In both cases general anaesthesia was induced by thiopentone and maintained by nitrous oxide and oxygen.

Hysterectomy was necessary after vaginal termination in six patients. In three of these the damage to the uterus involved the uterine vessels, resulting in extensive broad ligament and retroperitoneal haematomata. In two cases the damage to the uterine vessels caused a haemoperitoneum-one of these needed 13 pints ( 7.4 litres) of blood. The sixth patient had recurrent haemorrhages over a period of four months after termination and despite three transfusions her haemoglobin level fell to $40 \%$ and hysterectomy had to be undertaken.

Histological examination of all excised specimen failed to reveal any abnormalities.

Blood tranfusion was needed in $15(3.1 \%)$ patients after hysterotomy and in $20(2.3 \%)$ following vaginal termination. In most cases blood transfusion was needed at the time of operation. Total dose iron infusion was given in 14 cases, otherwise postoperative anaemia was treated by oral iron therapy.

\section{TRAUMA}

Perforation of the Uterus.-There were 23 (2.7\%) cases of definite perforation of the uterus. In 12 of them laparotomy was performed and the uterine wall was repaired in two layers-in one the small intestine was damaged and a 6-in $(15-\mathrm{cm})$ length had to be excised, and in another the mesentery was torn, thus depriving the bowel of its blood supply and again bowel excision had to be undertaken. In five cases hysterectomy had to be performed and one of these included a patient whose bladder was also perforated. Five cases were treated "conservatively" by close observation as it was thought that the perforation was small and no other internal organs had been damaged. In one case, in which the patient had vaginal termination with Utus paste, the diagnosis was missed and she died a week later at home (Sood, 1971).

Cervical Trauma.-This occurred in $20(2.4 \%)$ cases; in most of them it was minor and due to the vulsellum forceps and was easily repaired. In two cases the laceration occurred during dilatation and extended almost to the internal os, and this required very careful surgery to restore the integrity of the cervix.

\section{VENOUS THROMBOSIS}

Deep vein thrombosis occurred in five patients who had hysterotomy, including one who had had deep venous thrombosis on two previous occasions. One of these had a pulmonary embolus from which she made a satisfactory recovery. In contrast, this complication did not occur after vaginal operations.

Superficial venous thrombosis followed in three cases but again it did not occur after vaginal termination.

\section{PARALYTIC ILEUS}

One case occurred after hysterotomy and sterilization at 12 weeks' gestation. Spontaneous bowel activity returned after three days of gastric aspiration, intravenous therapy, and sedation. The cause was thought to be due to postoperative intraperitoneal haemorrhage.

\section{CARDIAC ARREST}

In one case the heart stopped at the end of hysterotomy while the patient was still under general anaesthesia. She was resuscitated successfully.

\section{DEATH}

Death occurred in one case after termination of pregnancy by insertion of Utus paste (Sood, 1971).

\section{OTHER COMPLICATIONS}

In four cases of vaginal termination the fetus was passed after discharge from hospital. These may have been cases of twin pregnancy or single pregnancy where the fetus was not removed. 
In one case of unsuspected twin pregnancy one fetus was left behind at hysterotomy and it continued to thrive and was subsequently born by normal delivery (Sood, 1970).

Five patients were found not to be pregnant and in one of these the uterus was perforated at the site of a scar due to a previous lower segment caesarean section and a laparotomy was undertaken to repair the damage to the uterus.

\section{Comment}

The overall morbidity of this series was $16.8 \%$, excluding urinary tract infection. This often occurred in conjunction with other complications and is therefore considered separately. The complication rate of abdominal surgery was higher $(19.3 \%)$ compared with vaginal termination (15.3\%). There were some outstanding differences between certain types of complications that followed abdominal and vaginal termination. Chest infection was much commoner after abdominal surgery and the reasons for this would seem to be due to longer periods of anaesthesia and shallow breathing due to postoperative pain. Venous thrombosis was exclusively confined to abdominal surgery and would seem to be related to longer anaesthesia and restriction in postoperative activity. Whether there is a differential change in the constituents of blood is not known. The urinary tract infection rate was very high after abdominal surgery but this pronounced difference was due to the fact that while routine preoperative catheterization was performed in abdominal surgery, this was not the case before vaginal terminations. Re-evacuation of the uterus after hysterotomy was required in $2.3 \%$ of cases, and in all of them irregular bleeding due to retained products of conception occurred. Thorough evacuation of uterine cavity is obviously most essential to prevent this complication.

There was one case of maternal death, which followed termination by Utus paste.

I wish to thank the consultants in gynaecology for permission to publish this paper. I thank Mrs. K. Sood, who helped in compiling the data on which this article is based, and Mr. C. W. F. Burnett for much helpful advice.

\section{References}

Chief Medical Officer of the Department of Health and Social Security (1970). Annual Report for 1969. London, H.M.S.O.

Diggory, P. L. C. (1969). Lancet, 1, 873.

Kerslake, O., and Casey, D. (1967). Obstetrics and Gynecology, 30, 35. Lakomy, T. (1968). Ginekologia Polska, 39, 863. Lindahl, J. (1959). Somatic Complications following Legal Abortion. Stockholm,
Scandinavian University Books.

Potts, D. M. (1970). British Medical Bulletin, 26, 65.

Sood, S. V. (1970). British Medical fournal, 4, 495

Sood, S. V. (1971). British Medical fournal 2, 315.

Sternadel, Z., Wendolowski, W., and Jablouski, Z. (1968). Ginekologia Polska, 39, 1127.

Vladov, E., Ivanov, I., Angelov, A., and Rakilovska, I. (1965). Gynaecologia, 159,54 .

\section{PRELIMINARY COMMUNICATIONS}

\section{Aluminium in Bone from Patients with Renal Failure}

\author{
VICTOR PARSONS, CHRISTINE DAVIES, \\ CLIFFORD GOODE, CHISHOLM OGG, \\ J. SIDDIQUI
}

British Medical fournal, 1971, 4, 273-275

\section{Summary}

Some samples of bone from patients with renal failure contained more aluminium than others, and the concentration tended to be highest in patients who had been uraemic or on dialysis longest. The significance of the association of raised concentrations of aluminium in bone with renal failure is discussed.

\section{Introduction}

During a study of the concentration of various ions in bone in patients with renal failure (Prosser et al., 1970) some samples

King's College Hospital, London S.E.5

VICTOR PARSONS, D.M., M.R.C.P., Physician

CHRISTINE DAVIES, Research Assistant

Atomic Weapons Research Establishment, Aldermaston, Berks

CLIFFORD GOODE, B.SC., A.R.I.C., Principal Scientific Officer

Guy's Hospital, London S.E.1

CHISHOLM OGG, M.D., M.R.C.P., Nephrologist

Wellcome Research Laboratory, Royal Victoria Infirmary, Newcastle upon Tyne NE1 4LP

J. SIDDIQUI, M.B., B.S., Research Fellow were found on neutron activation analysis to contain more aluminium than others. The results of the complete analysis will be reported elsewhere, but in view of the recent interest in the absorption of aluminium during the treatment of hyperphosphataemia of renal failure (Berlyne et al., 1970) we are making a preliminary report of our findings.

\section{Methods}

The bone samples had been obtained for biopsy or at necropsy from the iliac crests, lumbar vertebrae, or ribs of patients who had no evidence of renal disease and of patients with terminal renal failure sustained by either dietary restriction or regular dialysis therapy. Each of the samples was divided. One part was fixed for microscopical examination and the other part was weighed wet, dried at $100^{\circ} \mathrm{C}$ for 12 hours, and then ashed for similar periods at $200^{\circ}, 400^{\circ}$, and $600^{\circ} \mathrm{C}$ in a muffle furnace. After each period of ashing the samples were weighed again. Samples of $10-100 \mathrm{mg}$ were subjected to neutron activation analysis. For the determination of fluorine, firstly, $14 \mathrm{MeV}$ neutrons from a Cockcroft-Walton generator (using positron counting for the ${ }^{18} \mathrm{~F}$ produced) were used, and, secondly, thermal neutrons in a Herald reactor. In the latter method the induced activity is measured by sequential counting using $\gamma$-spectometry, which enables the concentrations of calcium, sodium, aluminium, and chloride to be determined (England et al., 1968; Goode et al., 1971).

\section{Results}

Because of variations in the amount of cancellous and cortical bone in the samples and the non-representative nature of solitary iliac crest biopsy specimens, a simple expression of the content of aluminium in wet or ashed bone gave very variable results. We were surprised at the constancy of the calcium 